\title{
SENSITIVITY ANALYSIS OF STAINLESS STEEL REFLECTOR FOR VR-1 TRAINING REACTOR
}

\author{
Jan Frybort ${ }^{1}$, Lubomir Sklenka $^{1}$, Filip Fejt ${ }^{1}$, Pavel Suk ${ }^{1}$ and Lenka Frybortova ${ }^{1}$ \\ ${ }^{1}$ Czech Technical University in Prague \\ Department of Nuclear Reactors, V Holesovickach 2, 18000, Prague, Czech Republic \\ jan.frybort@fjfi.cvut.cz, lubomir.sklenka@fjfi.cvut.cz
}

\begin{abstract}
Pressurized water reactors are typically surrounded in the radial direction by neutron reflectors made from stainless steel and water. These reflectors decrease neutron leakage and provide protection of pressure vessel from fast neutrons damaging its integrity. Such a radial reflector influences multiplication factor of the core and distribution of neutron flux and fission power inside the core. All these effects can be analyzed by full-core simulations using macroscopic constants. Methodology for generation of the macroscopic constants for non-fuel regions will be tested for new stainless steel reflectors at the VR-1 reactor. Rods from SS 3041 material will be used for construction of radial reflectors for the VR-1 reactor. They will be design to generate sufficient measurable response in selected core characteristics. The study is focused on core power distribution and reactivity worth of absorbing rods in a VR-1 reactor core. The core typically consists of about 20 IRT-4M fuel assemblies and seven absorbing rods UR-70. Replacing water surrounding the core by several reflector assemblies containing stainless steel will influence leakage and distribution of neutrons inside the core. The current analysis deals with local effects and employs the sensitivity study to discover the nature of reflectors' impact on the reactor core. These effects were studied even for several past VR-1 reactor core configurations. All calculations were carried out in Serpent2 Monte-Carlo code with various evaluated libraries: ENDF/B-VII.1, ENDF/B-VIII.0, and JEFF-3.3 data.
\end{abstract}

KEYWORDS: VR-1 Reactor, sensitivity, reflector, nuclear data, power distribution

\section{INTRODUCTION}

Radial reflectors surrounding any light-water reactor core are an integral part of the reactor design [1]. It is necessary to be able to respect their parameters in full-core calculations [2]. It is therefore necessary to have validated methods for macroscopic data generation for the reflectors. The validation process can be greatly facilitated by availability of experimental data for core configurations with and without reflectors. It is even more valuable if a full-core Monte-Carlo calculation of the core characteristics is available. That is the aim of this project.

This article describes properties of a proposed design of radial stainless steel reflector assemblies for VR-1 reactor core. The core would be partly reflected by these reflector assemblies. The rest of the core is surrounded by water. Design and influence of the stainless steel reflectors is explained together with calculations showing the multiplication factor sensitivity to the dominant reactions in the reflector. Effect of alternative evaluated date is also demonstrated. 


\section{ANALYZED REACTOR AND TOOLS}

The Training reactor VR-1 is the key part of this research. It will be used for future experiments, thus the computational analysis was conducted for this system. Versatility of the reactor core was utilized and several core configurations were included together with specific core layout proposed for this analysis. Description of the main parameters of the VR-1 reactor follows.

\subsection{Training Reactor VR-1}

Training reactor VR-1 is an experimental zero-power reactor with open pool. It uses IRT-4M fuel assemblies. The great advantage of this reactor is variability of its core. It typically contains about 20 fuel assemblies, seven absorbing rods, and several dry vertical channels for measurement and experiments. The core is typically reflected by water.

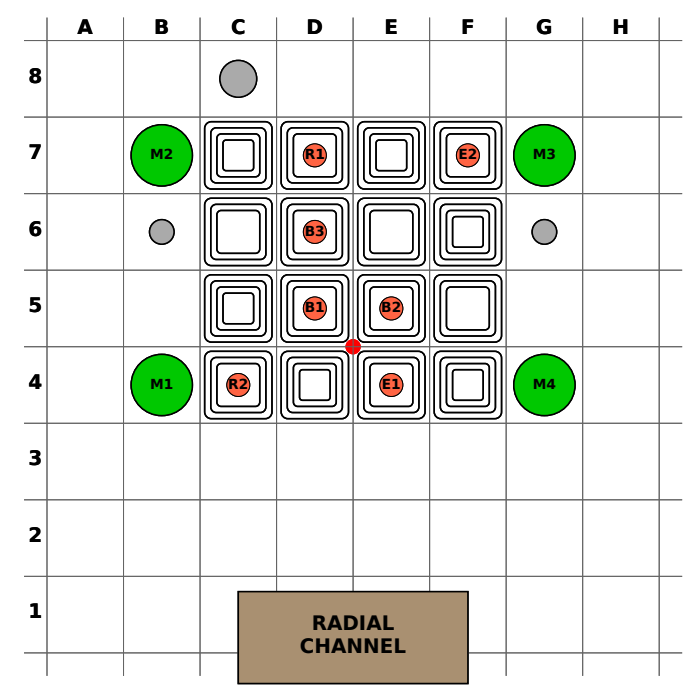

(a) $\mathrm{C} 7$ reactor core
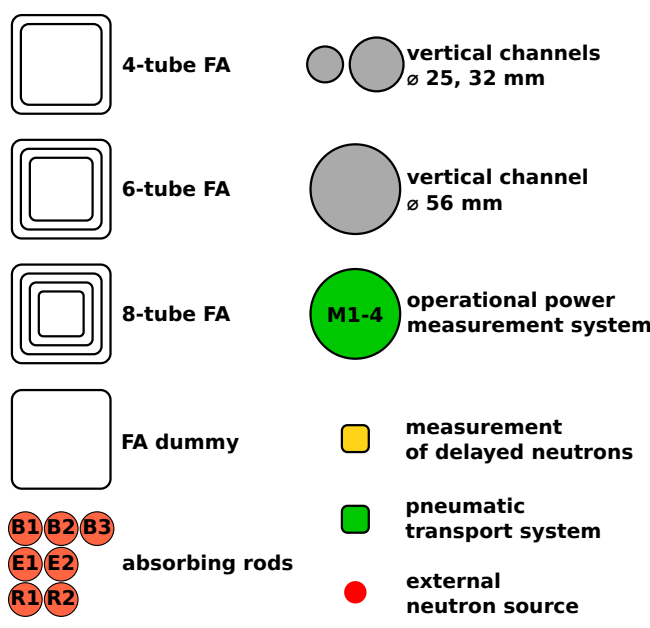

(b) Core components

Figure 1: One of the evaluated VR-1 reactor cores

\subsection{Design of Stainless Steel Reflectors for VR-1}

It is necessary to introduce first the design of the stainless steel reflectors. Fig. 2 shows the current design. It consists of $3150 \mathrm{~cm}$ long stainless steel rods from SS 3041 material [3], four stainless steel structural rods, grids, and bottom nozzle to fit into the reactor grid. There is also potential to insert a vertical channel in the center of the assembly at the expense of seven 3041 rods. Results with this modification are not shown in this study.

The VR-1 reactor cores analyzed in this study are plotted in Fig. 3 from Serpent2 plotter [4]. These models already include the stainless steel reflectors. Cores without these reflectors were also calculated for evaluation of the reflector effects. The reflectors are in these cores replaced by an empty core position filled with water. 


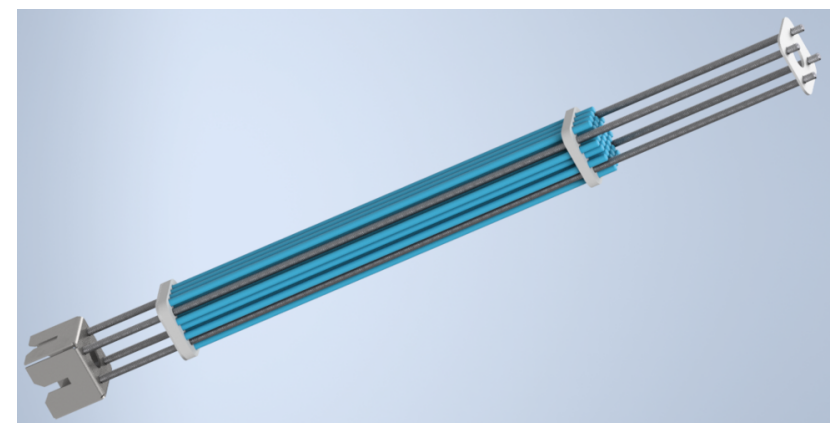

Figure 2: Design of VR-1 stainless steel reflectors

\subsection{Computational tools}

All simulations were carried out in Serpent2 Monte-Carlo code in version 2.1.31. ENDF/B-VIII.0 cross-section data are used by default [5], but influence of alternative ENDF/B-VII.1 and JEFF-3.3 data was also evaluated [6].

\section{RESULTS}

The effect of stainless steel reflectors was analyzed by calculations from several perspectives including multiplication factor sensitivity. Cases with and without these reflectors were compared and the calculations were conducted with various evaluated nuclear data.

\subsection{Neutron Flux and Core Characteristics}

The primary response of the reactor core to the presence of the stainless steel reflectors is change of thermal neutron flux distribution in the core, reactivity change of the core, and change in the absorbing rods' worths.

The first plot in this section in Fig. 4 shows reactivity worths of either E1 or E2 absorbing rods used for compensation of reactivity changes caused by experimental equipment or R1 rod used for regulating the core reactivity. The presented results show reactivity in $\mathrm{pcm}$ that can be released by withdrawing the rod completely (it is usually partially inserted in the core) in the respective VR-1 reactor core. Included are $1 \sigma$ uncertainties.

It is clear from the results plotted in Fig. 4 that presence of the stainless steel reflectors has only limited influence on the rod worths and the change is not statistically important, i.e. it is not greater than $1 \sigma$ uncertainty of the calculations.

Another important characteristic is reactivity worth of the stainless steel reflectors. Simple Tab. 1 shows how much reactivity in pcm is lost due to replacement of water reflecting the core by the stainless steel reflectors. Reactivity always decreases due to the stainless steel reflectors because of the small VR-1 reactor core dimensions and high neutron leakage. It is clear that the core 


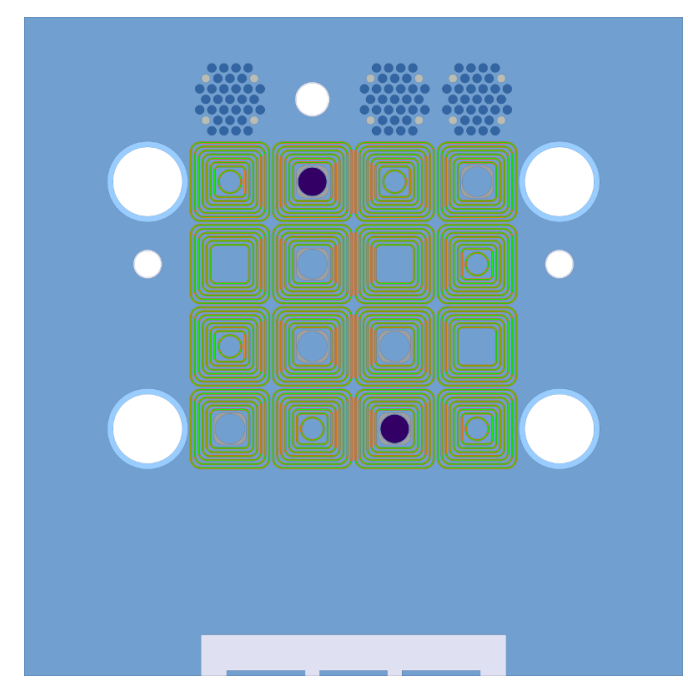

(a) $\mathrm{C7}$ reactor core

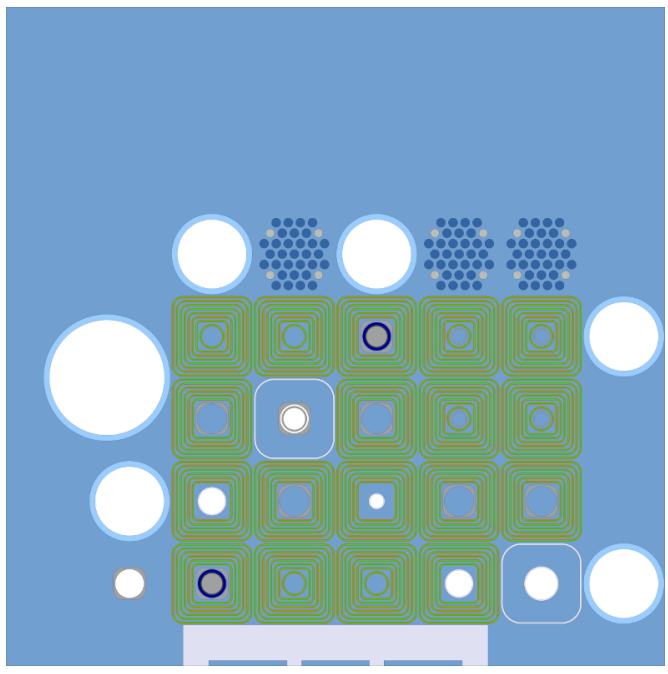

(c) $\mathrm{C13}$ reactor core

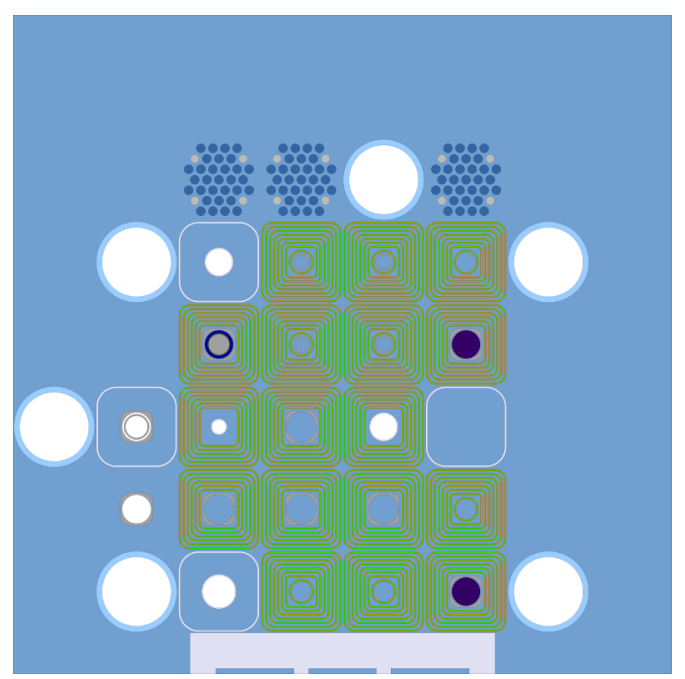

(b) $\mathrm{C11}$ reactor core

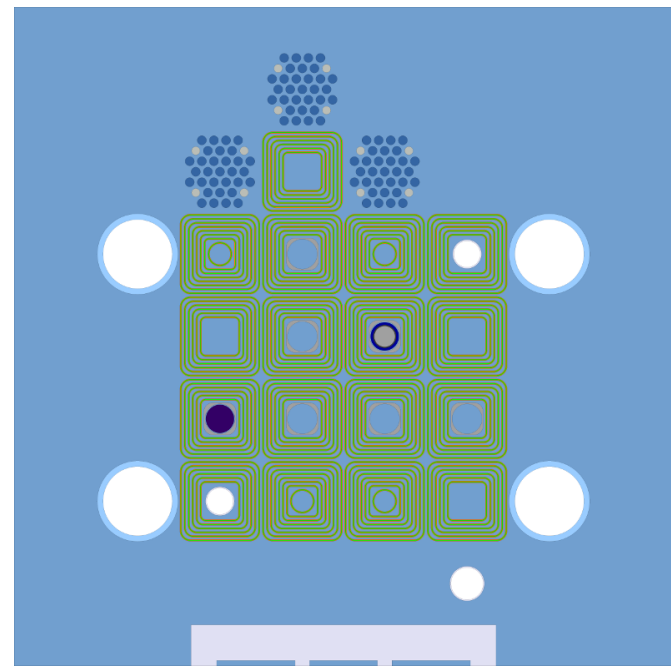

(d) New proposed CX reactor core

Figure 3: Analyzed core of the VR-1 reactor

configuration is crucial for this characteristic. The special core configuration CX is well designed as it shows the greatest reactivity worth.

Table 1: Reactivity worths of the reflectors

\begin{tabular}{|c|c|c|c|}
\hline C7 & C11 & C13 & CX \\
\hline $649 \pm 11 \mathrm{pcm}$ & $402 \pm 11 \mathrm{pcm}$ & $704 \pm 12 \mathrm{pcm}$ & $1048 \pm 12 \mathrm{pcm}$ \\
\hline
\end{tabular}

The last global characteristic of the system is thermal flux distribution in the core. It was calculated 


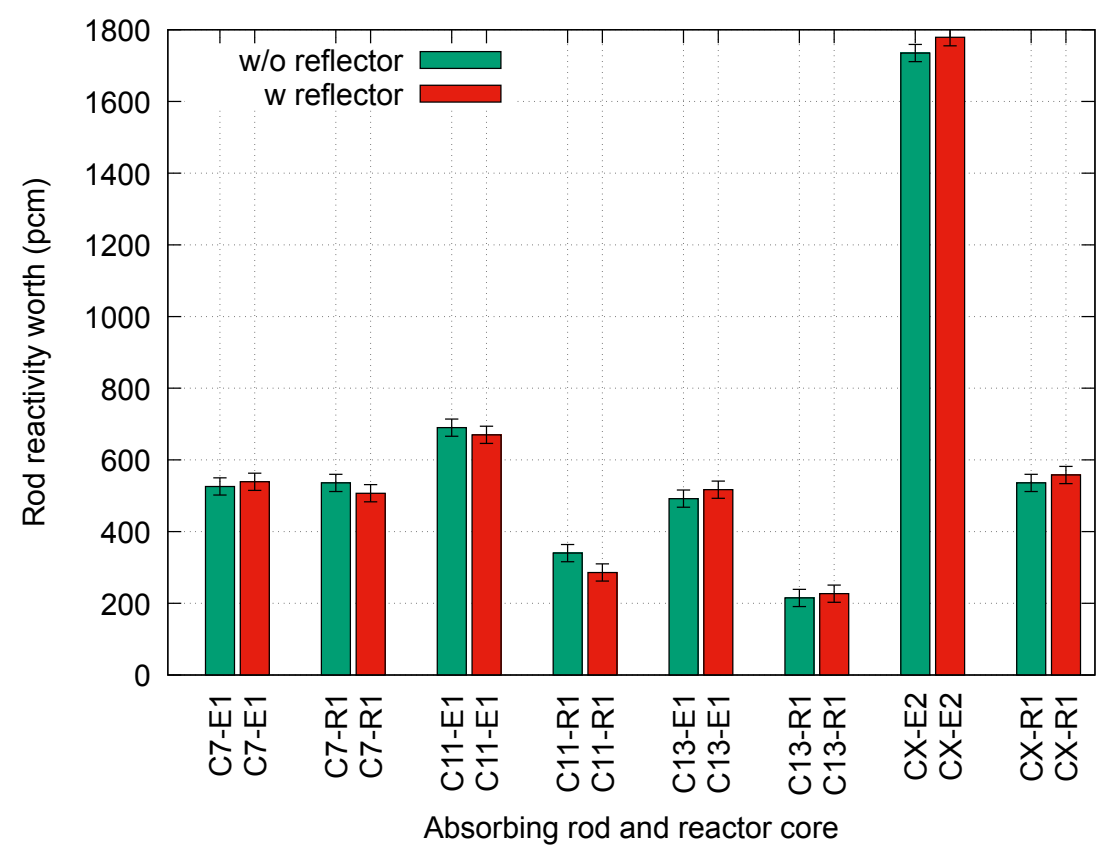

Figure 4: Reactivity compensated by rods in VR-1 cores with and without the stainless steel reflectors

by Serpent 2 mesh detector for each position in the core lattice. Generally, two cases with and without the reflectors were compared. Uncertainty of the calculation was kept below $0.2 \%$ in any position in the core. Plots in Fig. 5 show relative change of the thermal flux peaking caused by the reflectors from two perspectives. The first plot is for the theoretical state where the reflectors were installed, but the core was left in a subcritical state as a result of this change. The other plot is for a critical state, when the effect of the reflectors was compensated by movement of E2 absorbing rod (position E5).

The greatest change in a fuel element in the subcritical state in Fig. 5a can be observed in the fuel assembly surrounded by the reflectors. Its thermal flux peaking factor was reduced from 0.967 to 0.776. Thermal neutron flux on the opposite side of the core is slightly increased in a response to the presence of the reflectors. The critical core is more complicated. There the reflector effect is combined with movement of the absorbing rod in position E5. A sharp thermal flux increase can be observed in the lower row of fuel elements as a result of these two effects.

\subsection{Multiplication Factor Sensitivity}

It was shown previously that installation of the stainless steel reflectors leads to multiplication factor decrease of the evaluated VR-1 reactor cores. Serpent 2 collision history based perturbation method was employed to assess sensitivity of the multiplication factor to cross-section in the stainless steel material of the reflectors. The sensitivity is presented first as energy integrated for elastic scattering and radiative capture cross-section. Then it is plotted in SCALE 56group structure [7] for the CX core (see Fig. 7). All results are for the alternative evaluated data. Finer lines in the the 


\begin{tabular}{|c|c|c|c|c|c|c|c|}
\hline $\begin{array}{cr}1 & W \\
-0.021\end{array}$ & $\begin{array}{|cr|}2 & W \\
-0.059\end{array}$ & $\begin{array}{cr}3 & W \\
-0.155\end{array}$ & $\begin{array}{cr}4 & W \\
-0.297\end{array}$ & $\begin{array}{cr}5 & W \\
-0.131\end{array}$ & $\begin{array}{cr}6 & W \\
-0.036\end{array}$ & $\begin{array}{cc}7 & W \\
0.006\end{array}$ & $\begin{array}{cc}8 & W \\
0.034\end{array}$ \\
\hline $\begin{array}{l}9 \quad \mathrm{~W} \\
0.001\end{array}$ & $\begin{array}{cr}10 & W \\
-0.101\end{array}$ & $\begin{array}{cr}11 \quad W \\
-0.303\end{array}$ & & $\begin{array}{c}13 \quad W \\
-0.286\end{array}$ & $\begin{array}{cr}14 \quad W \\
-0.058\end{array}$ & $\begin{array}{l}15 \quad W \\
0.037\end{array}$ & $\begin{array}{l}16 \quad \mathrm{~W} \\
0.060\end{array}$ \\
\hline $\begin{array}{l}17 \quad \mathrm{~W} \\
0.028\end{array}$ & \begin{tabular}{|cr}
$18 \quad W$ \\
-0.105
\end{tabular} & & $\begin{array}{cr}20 & F \\
-0.198\end{array}$ & & $\begin{array}{c}22 \quad W \\
-0.080\end{array}$ & $\begin{array}{l}23 \quad \mathrm{~W} \\
0.068\end{array}$ & $\begin{array}{l}24 \quad W \\
0.075\end{array}$ \\
\hline $\begin{array}{l}25 \quad \mathrm{~W} \\
0.043\end{array}$ & $\begin{array}{|ll|}26 & \text { W } \\
0.024\end{array}$ & $\begin{array}{cr}27 & F \\
-0.034\end{array}$ & $\begin{array}{lr}28 & F \\
0.033\end{array}$ & $\begin{array}{cc}29 & F \\
-0.033\end{array}$ & $\begin{array}{lr}30 & F \\
0.050\end{array}$ & $\begin{array}{ll}31 & W \\
0.083\end{array}$ & $\begin{array}{l}32 \quad W \\
0.083\end{array}$ \\
\hline $\begin{array}{l}33 \quad \mathrm{~W} \\
0.071\end{array}$ & $\begin{array}{l}34 \quad W \\
0.079\end{array}$ & $\begin{array}{lr}35 & F \\
0.086\end{array}$ & $\begin{array}{lr}36 & F \\
0.091\end{array}$ & $\begin{array}{lr}37 & F \\
0.095\end{array}$ & $\begin{array}{l}38 \quad F \\
0.100\end{array}$ & $\begin{array}{ll}39 & W \\
0.103\end{array}$ & $\begin{array}{l}40 \quad W \\
0.096\end{array}$ \\
\hline $\begin{array}{l}41 \quad \text { W } \\
0.107\end{array}$ & $\begin{array}{l}42 \quad W \\
0.111\end{array}$ & $\begin{array}{l}43 \quad F \\
0.114\end{array}$ & $\begin{array}{lr}44 \quad F \\
0.118\end{array}$ & $\begin{array}{lr}45 \quad F \\
0.120\end{array}$ & $\begin{array}{l}46 \quad F \\
0.121\end{array}$ & $\begin{array}{ll}47 & W \\
0.121\end{array}$ & $\begin{array}{ll}48 \quad W \\
0.123\end{array}$ \\
\hline $\begin{array}{l}49 \quad W \\
0.126\end{array}$ & $\begin{array}{l}50 \quad W \\
0.124\end{array}$ & $\begin{array}{lr}51 \quad F \\
0.132\end{array}$ & $\begin{array}{l}52 \quad F \\
0.131\end{array}$ & $\begin{array}{l}53 \quad F \\
0.133\end{array}$ & $\begin{array}{lr}54 & F \\
0.134\end{array}$ & $\begin{array}{lr}55 & W \\
0.130\end{array}$ & $\begin{array}{ll}56 & W \\
0.134\end{array}$ \\
\hline $\begin{array}{l}57 \quad \text { W } \\
0.127\end{array}$ & $\begin{array}{l}58 \quad W \\
0.127\end{array}$ & $\begin{array}{l}59 \quad \text { W } \\
0.138\end{array}$ & $\begin{array}{ll}60 & W \\
0.136\end{array}$ & $\begin{array}{l}61 \quad \text { W } \\
0.138\end{array}$ & $\begin{array}{l}62 \quad W \\
0.138\end{array}$ & $\begin{array}{l}63 \quad \mathrm{~W} \\
0.133\end{array}$ & $\begin{array}{l}64 \quad W \\
0.130\end{array}$ \\
\hline
\end{tabular}

$\begin{array}{lllllllllll}\text { A } & \text { B } & \text { C } & \text { D } & \text { E } & \text { F } & \text { G } & \text { H }\end{array}$

(a) $\mathrm{CX}$ core in subcritical state

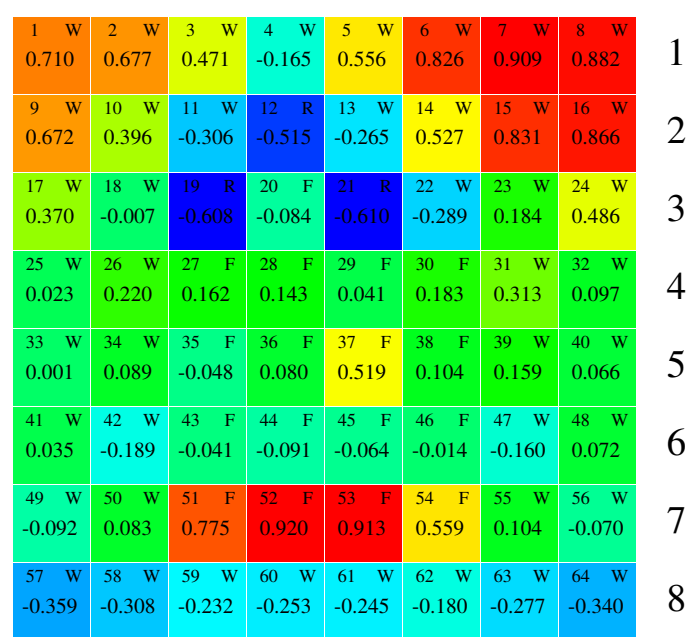

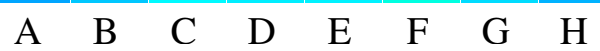

(b) $\mathrm{CX}$ core in critical state

Figure 5: Relative change of thermal neutron flux peaking in $\mathrm{CX}$ core caused by presence of stainless steel reflectors, $F$ indicates fuel element, $W$ water, and $R$ reflector

latter plot show $1 \sigma$ uncertainty boundaries.

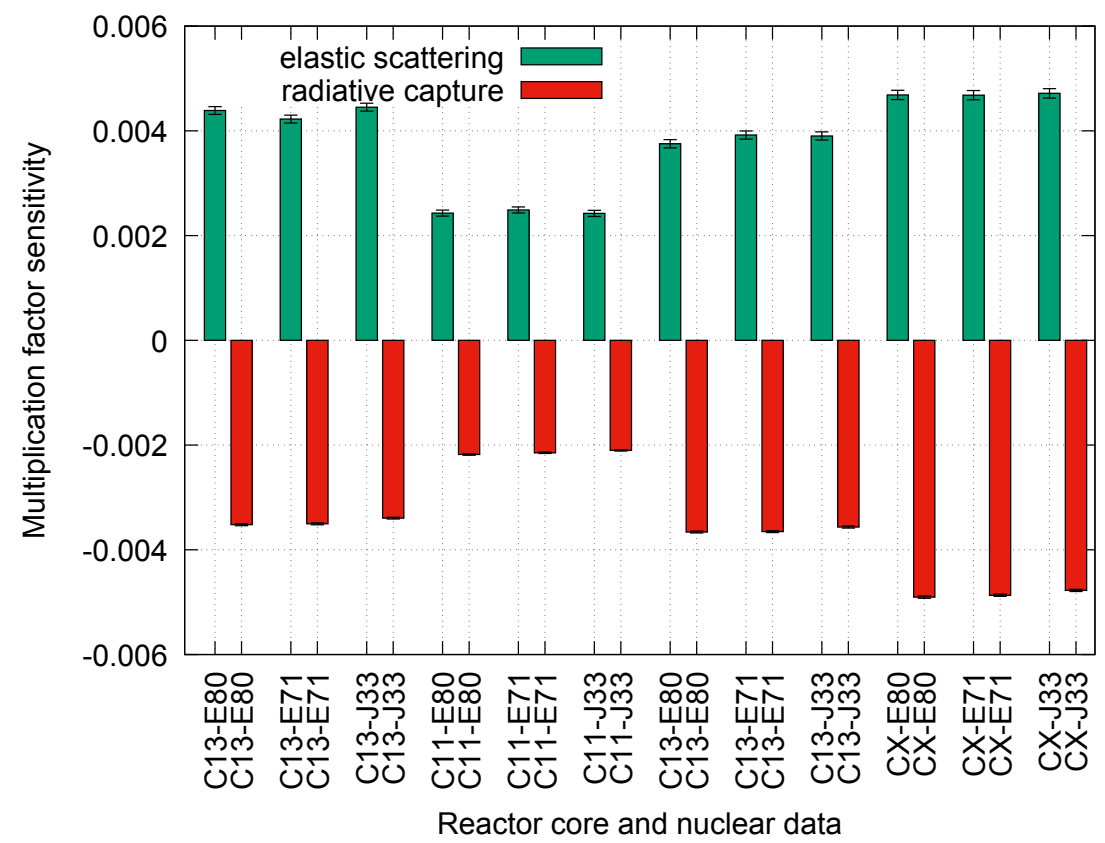

Figure 6: Energy integrated multiplication factor sensitivity in analyzed reactor cores to stainless steel in the reflector assemblies

It can be seen that the sensitivity analysis results are comparable among the evaluated data. The 


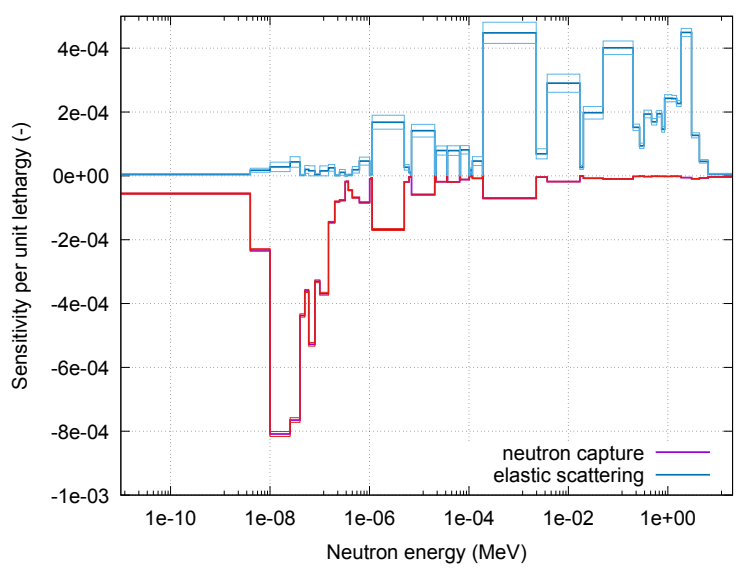

(a) Multiplication factor sensitivity using ENDF/B-VIII.0 data

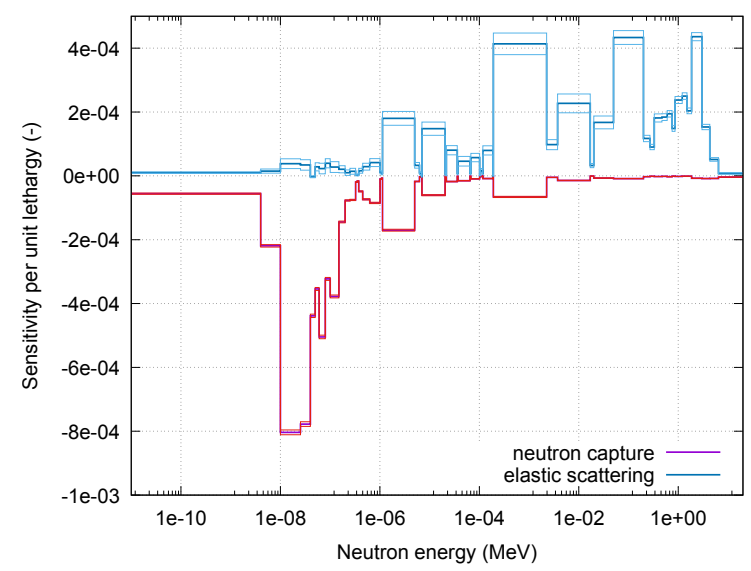

(b) Multiplication factor sensitivity using ENDF/B-VII.1 data

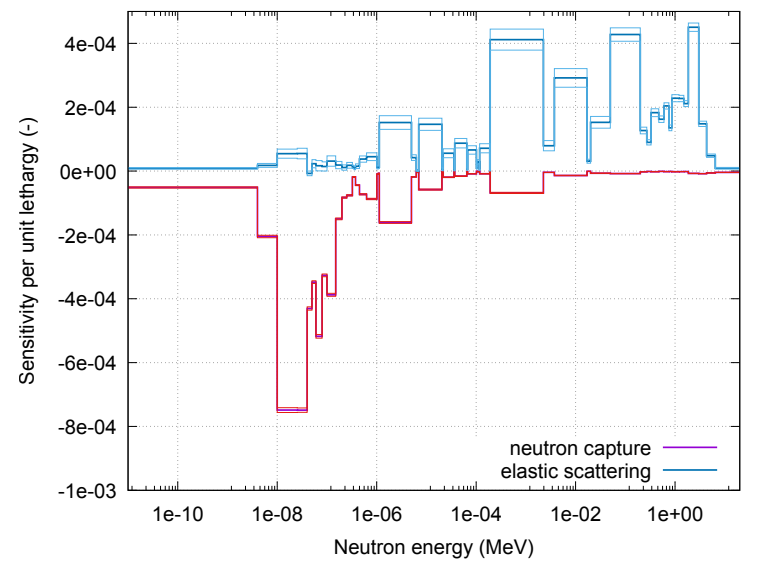

(c) Multiplication factor sensitivity using JEFF-3.3 data

Figure 7: Multiplication factor sensitivity to stainless steel in reflector assemblies in 56group structure for various nuclear data in $\mathrm{CX}$ core

energy integrated results in Fig. 6 revealed that elastic scattering and radiative capture sensitivity components are similar and the total effect depends on the analysed reactor core.

\section{CONCLUSIONS}

Analysis of the improved design of the stainless steel reflector assemblies was conducted for several VR-1 reactor core configurations. Calculations by Serpent2 Monte-Carlo code proved substantial effect of the core configuration on the observed characteristics. The new CX core proposed for future measurements was found to be the one with the greatest measurable effect of the reflectors.

The stainless steel reflectors substantially decrease multiplication factor the core. It is due to increased neutron leakage by water displacement around the core. It is necessary for future measurement to make a clear distinction between the theoretical subcritical state for evaluation of static 
characteristics of the reflectors and the critical state that must be achieved by movement of one of the absorbing rods in the core. The difference between these two states is clearly demonstrated on the relative change of thermal flux peaking factors in Fig. 5.

Various evaluated data were compared: ENDF/B-VII.1, ENDF/B-VIII.0, and JEFF-3.3. All proved to be comparable in the analysis. Even for the sensitivity analysis demonstrated in Fig. 7.

In conclusion, measurable characteristics alterations of the core characteristics were identified. It was demonstrated that the CX core selected for future experimental work is suitable for the measurements. The next stage will be calculation of macroscopic constants for the reflector assemblies and comparison of the Serpent 2 Monte-Carlo results with deterministic calculations and measurements.

\section{ACKNOWLEDGEMENTS}

This work was supported by the project no. CZ.02.1.01/0.0/0.0/16_013/0001790, financed from European structural and investment funds and Czech Republic funds.

Access to computing and storage facilities owned by parties and projects contributing to the National Grid Infrastructure MetaCentrum provided under the programme "Projects of Large Research, Development, and Innovations Infrastructures" (CESNET LM2015042), is greatly appreciated.

\section{REFERENCES}

[1] International Atomic Energy Agency, In-Core Fuel Management Code Package Validation for WWERs, IAEA, Vienna, Austria (1995).

[2] V. Krysl, M. Mikolas, D. Sprinzl, J. Svarny, ”Full-Core” VVER-1000 benchmark calculated by MOBY-DICK macrocode, SKODA JS, Pilsen, Czech Republic (2015).

[3] R. J. McConn Jr., Compendium of Material Composition Data for Radiation Transport Modeling, Pacific Nortwest National Laboratory, Richland, Washington, USA (2011).

[4] J. Leppänen, T. Viitanen, V. Valtavirta, T. Kaltiaisenaho, "The Serpent Monte Carlo code: Status, development and applications in 2013," Ann. Nucl. Energy 82, pp. 142-150 (2015).

[5] M. B. Chadwick, M. Herman, P. Oblozinsky, et al., "ENDF/B-VIII.0: The 8th Major Release of the Nuclear Reaction Data Library with CIELO-project Cross Sections, New Standards and Thermal Scattering Data," Nuclear Data Sheets, 148, pp. 1-142 (2018).

[6] A. Santamarina, D. Bernard, Y. Rugama, The JEFF-3.1.1 Nuclear Data Library, OECD NEA, Paris, France (2009).

[7] B. T. Rearden, M.A. Jessee, SCALE Code System, ORNL/TM-2005/39, Version 6.2.3, Oak Ridge National Laboratory, Oak Ridge, Tennessee, USA (2018). 